\title{
Boletim de Saúde Infantil e Juvenil - o exame global de saúde dos 11 aos 13 anos (parte I)
}

Cristina Freitas, ${ }^{*}$ Helena Sofia Sousa, ${ }^{* *}$ Helena Fonseca***

\section{RESUMO}

Na idade dos «11 aos 13» as transformações pubertárias acompanham a transição para o mundo das descobertas e da construção da autonomia. Tendo como base o Boletim de Saúde Infantil e Juvenil, os autores apresentam vários aspectos que devem ser contemplados pelo profissional de saúde quando da observação de um adolescente desta idade. São abordados os aspectos a englobar na anamnese através da utilização do acrónimo HEEADSSSSS, com o objectivo de avaliar os contextos de vida do adolescente e perceber qual o seu desenvolvimento cognitivo e psicossocial.

Palavras-chave: Adolescentes, promoção da saúde.

\section{INTRODUÇÃO}

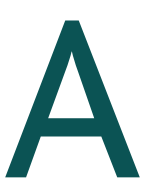

fase dos «11 aos 13» é um importante touch- point. Nesta idade as transformações pubertárias acompanham a transição para o mundo das descobertas e da construção da autonomia. Enquanto profissionais de saúde, ao atendermos um adolescente, seja no âmbito de uma consulta de vigilância de saúde, em cuidados diferenciados ou no serviço de urgência, a possibilidade de intervenção através da prestação de cuidados antecipatórios é uma oportunidade a não perder!

\section{TEMAS DE CONVERSA}

Na consulta dos 11-13 anos do Boletim de Saúde Infantil e Juvenil são propostos os seguintes temas de conversa: transformação pubertária, alimentação, prática desportiva, escola/família/amigos, tempos livres, sexualidade, segurança e acidentes, consumos nocivos. Os temas assemelham-se ao acrónimo HEEADSSSSS (home, education, eating, drugs, sleep, sexuality, suicide, security, support) amplamente utilizado em Medicina da Adolescência.

\footnotetext{
*Assistente Hospitalar de Pediatria, Hospital do Funchal.

**Assistente Hospitalar de Pediatria, Hospital de Reynaldo dos Santos.

***Chefe de Serviço, Unidade de Medicina do Adolescente, Departamento da Criança e da Família, Hospital de Santa Maria.
}

De acordo com a designação da OMS a fase dos 11 aos 13 anos corresponde à pré-adolescência. Nesta fase surgem movimentações crescentes de independência com menor interesse nas actividades familiares. As rápidas transformações físicas motivam uma maior preocupação com o próprio, com a sua imagem corporal, com necessidade de comparação do seu corpo com o dos pares. Simultaneamente ao afastamento progressivo da família, os amigos assumem uma importância crescente, com predomínio no relacionamento com adolescentes do mesmo sexo. Nesta fase cria-se um esboço do conceito de grupo, conceito este que é consolidado na adolescência média.

Em simultâneo com as transformações físicas, ocorre, a nível cognitivo, a evolução do pensamento concreto para o pensamento formal. É uma fase em que a autoridade é testada, sendo típico a falta de controlo da impulsividade e a necessidade de gratificação imediata que, em última instância, poderá resultar em comportamentos de risco.

Nesta idade o foco prioritário de atenção deverá ser desviado da família, até então o nosso interlocutor principal, para o adolescente. A anamnese reveste-se de características específicas que têm de ser treinadas, sendo um dos pontos fulcrais o garante da confidencialidade. 
É necessário explicar o seu significado e discutir as suas limitações, perante o próprio, os pais ou representante legal. Estudos comprovam que a anamnese se torna assim mais fiável e que melhora a adesão aos cuidados médicos. ${ }^{1,2} \mathrm{~A}$ entrevista clínica é também uma oportunidade para responsabilizarmos o adolescente pela sua saúde, ajudando-o a adquirir, também a este nível, autonomia, uma das tarefas fulcrais da adolescência.

\section{Alimentação}

Nesta fase há um aumento das necessidades nutricionais devido essencialmente ao aumento da estatura (cerca de $1 / 4$ da estatura em adulto é adquirida durante este período), peso (50\% do peso adulto), densidade óssea (40\%), massa muscular (duplica) e do volume sanguíneo. ${ }^{3}$ Os hábitos frequentemente modificam-se com um «saltar» de refeições e uma ingesta crescente de «fast food». Os adolescentes podem ainda enveredar por dietas especiais, nomeadamente as vegetarianas, por razões ecológicas, económicas, religiosas ou filosóficas. Assumindo-se que a ingesta nutricional é adequada, recomenda-se neste caso que as refeições tenham uma maior densidade calórica, menor quantidade em fibras e que seja suplementada com vitaminas (D e B12) e minerais (ferro e cálcio).

A mudança de hábitos, as dietas especiais e a menarca nas raparigas, são factores de risco que podem contribuir para défices nutricionais, sendo os mais prevalentes os défices em ferro, cálcio e zinco.

\section{Prática desportiva}

A prática desportiva associa-se a aspectos físicos e psicossociais que importa salientar, designadamente a percepção de auto-eficácia e controlo pessoal, a diminuição da ansiedade, a integração social e a prevenção e controlo de comportamentos de risco. As recomendações da Autoridade da Educação para a Saúde para a actividade física (AF) são de: 60 minutos de AF por dia, moderada; pelo menos, duas vezes por semana a $\mathrm{AF}$ deve ser direccionada para a força muscular, flexibilidade e saúde óssea; AF integrada nos estilos de vida, nomeadamente 11000 a 12000 passos para o sexo feminino e 13000 a 15000 passos para o sexo masculino. ${ }^{4}$

\section{Escola/amigos/família \\ Escola}

Em qualquer fase da adolescência temáticas como a escola, a família e os amigos são fundamentais numa anamnese.

Entre os 11 e os 13 anos surgem certamente mudanças de escola ou de turma, associadas a um menor suporte do adulto, a uma necessidade de maior autonomia, expectativas académicas mais elevadas, instituições mais impessoais, que podem culminar, em alguns casos, no incremento da ansiedade e redução do rendimento escolar. A participação em actividades curriculares e extra-curriculares tais como o desporto, a música ou o teatro, tem sido identificado como um factor facilitador da adaptação, um factor de reconhecimento positivo por parte do novo grupo, podendo influenciar positivamente o adolescente na escolha de comportamentos saudáveis.

\section{Amigos}

Na adolescência a amizade é um suporte fundamental para o desenvolvimento do adolescente. A confiança do adolescente nos amigos deve-se, em parte, à segurança que proporcionam em partilhar e experimentar de forma conjunta os conflitos, as angústias e as dificuldades. A pertença a um grupo não é uma característica dominante desta fase, contudo assume um papel crescentemente importante na promoção da autonomia, com possibilidade de tomada de decisão à margem da família; na definição da identidade; na segurança que confere no processo de «separação» da família. ${ }^{5} \mathrm{O}$ adolescente excluído, por circunstâncias extrínsecas ou intrínsecas, atravessa habitualmente um período de profundo mau estar.

No contexto do grupo surgem as tribos urbanas, grupos que se unem por partilharem os mesmos princípios, interesses, gostos musicais ou estéticos. Como exemplos: betos, góticos, hippies, dreads, emos, lolitas, sendo recentes estas duas últimas subculturas. Verifica-se, no entanto, que a maioria dos jovens adquire apenas, momentaneamente e sem compromisso definitivo, os seus elementos estéticos. ${ }^{6}$

\section{Família}

Em relação à família, considera-se que as tarefas da adolescência poderão ser facilitadas ou, pelo contrário, dificultadas pelo sistema familiar. ${ }^{7}$ Os pais permanecem como modelos importantes exercendo uma influência consistente e estabilizadora, especialmente à 
medida que os adolescentes se expõem aos vários comportamentos de experimentação. Em consulta teremos a oportunidade de discutir com a família as alterações vivenciadas nesta fase do ciclo de vida no sentido de facilitar a adaptação. Escutar o adolescente, transmitir mensagens claras, utilizar a negociação como uma ferramenta quotidiana, revelar interesse e preocupação pelas suas actividades, demonstrar confiança no adolescente, realçar os seus atributos positivos, colocar recursos ao seu alcance, respeitar a sua intimidade, são aspectos que deverão ser discutidos e competências que podem ser treinadas. De acordo com Steinberg, ${ }^{8}$ podemos considerar quatro estilos parentais, desde o estilo autoritário ao estilo desligado. O estilo com autoridade é o que apresenta melhores resultados psicossociais e que mais facilita o processo de autonomização, com melhores resultados escolares e maior auto-estima. Em suma, para crescerem bem, os adolescentes necessitam de limites firmes e explícitos, num ambiente de afecto e compreensão.

\section{Tempos livres}

Segundo dados do estudo «Health Behavior in School-aged Children» (HBSC) de 2006, ${ }^{9}$ os adolescentes portugueses ocupam os tempos livres essencialmente a ver televisão e com o computador: um terço passa mais de quatro horas por dia (dias úteis) a ver televisão e um número sobreponível passa entre uma a três horas em frente ao computador. Vários estudos apontam como consequência efeitos negativos sobre a saúde (obesidade, diminuição do rendimento escolar, comportamentos violentos). Como complemento aos sistemas de bloqueio, a Academia Americana de Pediatria preconiza a educação na área dos meios de comunicação e recomenda: limitar o tempo utilizado em frente dos vários ecrãs, a uma a duas horas por dia, retirar aparelhos de TV do quarto de dormir; monitorizar os programas observados; utilizar programas controversos para discutir temas como violência, sexualidade, drogas; encorajar actividades ao ar livre.

\section{Sexualidade}

A adolescência precoce caracteriza-se por comportamentos de auto-erotização e de auto-experimentação. Nesta fase e, caso a caso, pode ser importante a abordagem de alguns temas tais como a contracepção e as doenças sexualmente transmissíveis. Salientamos a ne- cessidade de não ter como garantida a orientação sexual do adolescente, não devendo ser especificado o sexo aquando da abordagem sobre namorados, podendo-se utilizar frases como: «Tens alguém especial ...?»

\section{Segurança e acidentes}

A importância da abordagem deste tema prende-se com os vários aspectos característicos deste grupo etário, nomeadamente a mudança de interesse da família para os amigos, sentimentos de invencibilidade e narcisismo, falta de experiência e maturidade e pobre capacidade de decisão. A mortalidade dos jovens é baixa quando comparada com a de idades posteriores, contudo é relevante do ponto de vista dos anos de vida perdidos, do impacto social e pelo facto de corresponder, numa parcela substancial, a mortes consideradas evitáveis. A título de exemplo, de acordo com o relatório da DGS, em 2003 observou-se, no grupo etário entre os 10 e os 14 anos, uma taxa de mortalidade de 7,8/100000 atribuída a causas violentas (acidentes, suicídios, homicídios), com duplicação dessa taxa no grupo etário seguinte (15-19 anos). Contudo realça-se um decréscimo progressivo na taxa de mortalidade em todos os grupos entre 1992 e 2003. ${ }^{10}$

\section{Consumos nocivos}

Ao falarmos em consumos nocivos torna-se importante considerar os factores motivacionais dos adolescentes para esta prática: afirmar uma nova identidade com condutas próprias dos adultos, ajuda para novas relações interpessoais, curiosidade, testar limites, prazer, pressão dos pares, desafio da autoridade, desejo de afirmação. Factores demográficos, sociais, emocionais, cognitivos estão igualmente associados a comportamentos de risco. Embora a exploração e a experimentação, habitualmente na companhia de pares, sirvam importantes propósitos relacionados com o desenvolvimento, a experimentação na adolescência pode também ter sérias consequências negativas a nível da saúde.

\section{Álcool}

Com base no estudo HBSC de $2006^{9}$ observamos que a prevalência de consumo de álcool não é muito elevada (1,5 a 3,5\%), mas por outro lado deparamo-nos com o facto de 9 a $15 \%$ destes adolescentes já terem tido um a três episódios de embriaguez. Neste contexto é im- 
portante avaliar o «binge drinking», que consiste no conceito de beber de forma abusiva em um curto espaço de tempo, e que quantitativamente é definido pelo consumo de cinco doses de álcool para o sexo masculino e quatro doses, para o sexo feminino.

\section{Tabaco e drogas}

Em relação à experimentação de substâncias ilícitas, a cannabis é a mais experimentada (11 anos: 1,9\%; 13 anos: $3,5 \%){ }^{9}$

\section{As nossas propostas}

Deixamos algumas sugestões de aspectos que consideramos importantes incluir numa futura versão do Boletim de Saúde Infantil e Juvenil de forma a melhorar o exame global de saúde dos «11-13 anos»:

- Inclusão sistemática do acrónimo HEEADSSSS (já com o último $S$ de «Support») na colheita dos dados da anamnese. Este $S$, baseado na teoria da resiliência, permitirá avaliar da existência de um adulto de referência na vida do adolescente, o que se tem revelado de uma grande importância. ${ }^{11}$

- Avaliação da percepção que o adolescente tem da sua imagem corporal e de como está a vivenciar as transformações que estão a ocorrer.

- Abordagem sistemática da avaliação da qualidade do sono.

- Alteração da denominação de prática desportiva para actividade física regular.

\section{REFERÊNCIAS BIBLIOGRÁFICAS}

1. Ford CA, Millstein SG, Halpern-Felsher BL, Irwin CE Jr. Influence of physician confidentiality assurances on adolescents' willingness to disclose in- formation and seek future health care: a randomized controlled trial. JAMA 1997 Sep 24; 278 (12): 1029-34.

2. Ford CA, Thomsen SL, Compton B.Adolescents' interpretations of conditional confidentiality assurances. J Adolesc Health 2001 Sep; 29 (3): 156-9.

3. American Academy of Pediatrics. Brigh Futures. Guidelines for Health Supervision of infants, children and adolescents. 3th Edition. Elk Grove Village, Il: American Academy of Pediatrics; 2008.

4. Cale L, Harris J. "Exercise recommendations for young people: an update", Health Educ 2001; 101 (3): 126-38.

5. Castellano Barca G, Hidalgo Vicario I, Redondo Romero AM., editores. Medicina de la adolescencia: Atención global. Madrid: Ergon; 2004.

6. 6. Sousa $\mathrm{H}$, Fonseca P. As tribos urbanas, as de ontem até às de hoje. Nascer e Crescer 2009; 18 (3): 209-14.

7. Fonseca H. Viver com adolescentes. Lisboa: Editorial Presença; 2005.

8. Steinberg L, Mounts NS, Lamborn SD, Dornbusch SM. Authoritative parenting and adolescent adjustment across varied ecological niches. J Research Adolesc 1991; 1: 19-36.

9. Matos MG, Simões C, Tomé G, Gaspar T, Camacho I, Diniz JA, et al. A Saúde dos Adolescentes Portugueses - Hoje e em 8 anos - Relatório Preliminar do Estudo HBSC 2006 - Relatório Português. Disponível em: http://www.fmh.utl.pt/aventurasocial/pdf/Relatorio_nacional_2006.pdf [acedido em 01/03/2011].

10. Laranjeira AR, Prazeres V. Mortalidade em idades jovens - Relatório 19922003. Lisboa: Direcção-Geral de Saúde; 2005.

11. Fonseca $\mathrm{H}$. Helping adolescents develop resilience: steps the pediatrician can take in the office. In: AM:STARs, Adolescent Medicine Clinics: State of the Art Reviews. Elk Grove Village, L:American Academy of Pediatrics; 2010. p. $152-60$.

\section{CONFLITOS DE INTERESSE}

As autoras não têm qualquer conflito de interesse.

\section{ENDEREÇO PARA CORRESPONDÊNCIA \\ Helena Fonseca \\ Departamento da Criança e da Família, Hospital de Santa Maria, Av. Prof. Egas Moniz, 1, 1649-028 Lisboa. \\ E-mail: helenaregalofonseca@gmail.com}

Recebido em 29/12/2010

Aceite para publicação em 14/04/2011

\section{ABSTRACT}

\section{BOLETIM DE SAÚDE INFANTIL E JUVENIL - GLOBAL HEALTH CHECK AT 11-13 YEARS OLD (PART I)}

By the age of 11-13, pubertal changes are associated with the transition to a world of discoveries and the construction of autonomy. Having as a basis the Boletim de Saúde Infantil e Juvenil, the authors discuss the most relevant aspects that must be taken into account by the health professional when consulting an adolescent of this age. The clinical interview is conducted based on the HEEADSSSSS acronym. The objective is to assess the adolescent's life context and understand how her/his cognitive and psychosocial development is being processed.

Keywords: Adolescent; Health Promotion. 